\title{
Is Calcitonin Receptor Gene (CTR) Polymorphism an Appropriate Marker for Calcium Oxalate Urolithiasis?
}

\author{
R. D. Mittal, H. K. Bid, R. Kumar, A. Kumar and M. Bhandari \\ Department of Urology, Sanjay Gandhi Postgraduate Institute of Medical Sciences, \\ Lucknow 226 014, Uttar Pradesh, India
}

KEY WORDS Calcitonin receptor; single nucleotide polymorphism; urolithiasis; polymerase chain reaction

\begin{abstract}
Formation of kidney stones is still unclear and is hypothesized to be associated with calcitonin receptor (CTR gene). The most frequently seen polymorphism within the CTR gene is Alu 1, which has been suggested as a genetic marker in search for the cause of urolithiasis. We evaluated the association between calcium oxalate stone disease and the Alu 1 polymorphism in North Indian patients. Blood samples from a control group of 105 healthy individuals and a group of 100 patients were taken.The CTR gene polymorphism was determined using Polymerase chain reaction (PCR) followed by restriction digestion. Associations between calcium oxalate stone disease and AluI polymorphism of CTR gene were evaluated statistically. The distribution of leucine (cuttable) homozygote in the stone patients though higher $(13 \%)$ as compared to the control group $(5.7 \%)$ was not statistically significantly (p= $0.185)$. The Odds ratio for the leucine allele of calcitonin receptor gene in calcium oxalate stone disease was 0.795 (95\% CI; 0.095-6.591). No significant association between Alu1 polymorphism of CTR gene and calcium oxalate stone formation was observed. Therefore Alu1 polymorphism of CTR gene at $1377^{\text {th }}$ nucleotide position may not authenticate as a suitable marker for risk assessment of urinary stone disease.
\end{abstract}

\section{INTRODUCTION}

Urolithiasis is a complex and multifactorial disease. The cause of calcium oxalate stone formation is heterogeneous and might involve both genetic and environmental factors .Although the genetic causes have been studied extensively; no chromosomal mapping has been achieved in stone patients with idiopathic hypercalciurea (Danpure 2000). The only conclusive comment of some genetic study is that urolithiasis is a polygenic defect and partially penetrative (Coe et al. 1992; Goodman et al. 1997). Recently, single nucleotide polymorphism; (SNPs) has been used as a tool for mapping the complex disease genes (Loder 1999). However, identifying a genetic marker with significant association with the susceptibility to urinary stone disease presents an important challenge.

Hypercalciurea is a well recognized risk factor associated with calcium oxalate stone urolithiasis and is usually treated to reduce the future incidences of stone formation. The calcitonin

Address correspondence to: R.D. Mittal, Associate Professor (Biochemistry), Department of Urology, Sanjay Gandhi Postgraduate Institute of Medical Sciences, Lucknow 226 014, Uttar Pradesh, India

Fax: 91-522-2668017.

Email: rmittal@sgpgi.ac.in ramamittal@yahoo.com receptor gene (CTR) is a 7-pass transmembrane G-protein coupled receptor which reacts in response to calcium metabolism related hormone calcitonin and they are known to occur in osteoclasts (Nicholson et al. 1986). Masi et al. (1998) in their study observed a marked connection between the CTR gene C/T polymorphism and bone mass density. Similarly, a $\mathrm{C} / \mathrm{T}$ variation altered the encoded amino acid from proline to leucine as reported by Nakamura and coworkers (1997) in Japanese population. Recently the CTR gene polymorphism has also been shown to be associated with calcium oxalate stone disease in Taiwanese patients where presence of leucine (T) allele is higher in stone patients as compared to controls (Chen et al. 2001). However various studies suggest subtle differences in CTR gene polymorphism even in normal healthy individuals in different populations and ethnic groups (Chen et al. 2001; Wolfe et al. 2003).

The present study was therefore planned to analyze Alu 1 CTR gene polymorphism in the North Indian population to evaluate their association with urolithiasis.

\section{MATERIAL AND METHODS}

Patient Selection: One hundred and five healthy volunteers (mean age -30) with no familial history 
of stone disease, or renal calcification (following renal ultrasonography tests, as well routine tests made from urinary microscopic hematuria) constituted the control group. Patients with recurrent calcium oxalate stones who had been treated from 1999-2002 in the department of Urology SGPGIMS were included in this study. Serial blood and urine biochemistry tests were undertaken to exclude the possibility of hypercalcemia, hyperuricemia, hyperuricosurea. Patients with urinary tract infection (UTI) during the course of study were excluded. Informed consent was obtained from both groups in this study. The genomic DNA was isolated from peripheral blood by using standard phenol chloroform method (Blin and Stafford 1976).

Polymerase Chain Reaction: PCR analysis of the CTR gene polymorphism was carried out to a total volume of $50 \mathrm{ml}$, containing 100-150ng genomic DNA; 4 pmol of each primer; $1 X$ Taq polymerase buffer and 0.25 units of Taq DNA Polymerase (Bangalore Genei India). The primers for the calcitonin receptor gene polymorphism were forward (5' - CTCAGTGATCACGATA CTGTG-3') and backward (5'-ATTCAGTGGA ACCAGCGTTGG-3') according to Masi et al ${ }^{7}$. PCR amplification was performed in a programmable thermal cycler PTC-100 (Peltier Thermal Cycler, MJ Research USA). The cycling condition were set as follows: $94^{\circ} \mathrm{C}$ for $5 \mathrm{~min}, 35$ cycles at $95^{\circ} \mathrm{C}$ for $30 \mathrm{~s}, 55^{\circ} \mathrm{C}$ for $30 \mathrm{~s}$ and $72^{\circ} \mathrm{C}$ for $30 \mathrm{~s}$ and one cycle of extension at $72^{\circ} \mathrm{C}$ for $10 \mathrm{~min}$. The 228 bp PCR product obtained from above reaction was digested overnight at $37^{\circ} \mathrm{C}$ with 1.5 units of Alu 1 (Fermentas) restriction enzyme. $5 \mathrm{ml}$ of the products was separated on a $9 \%$ PAGE (Polyacrylamide gel electrophoresis) and visualized with ethidium bromide. The restriction site was located at the CTG codon encoding the amino acid leucine forming a cuttable site. In case of CCG encoding the amino acid proline will remain intact as there is no cuttable site. If the product is excised, two fragments of 120 and $108 \mathrm{bp}$ will be present.

For statistical analysis, genotype distributions in the control and stone patient groups were compaired using the $\mathrm{c} 2$ and Fisher's exact test. The allelic frequency of T vs. C alleles was calculated in both groups. Odds ratio $(\mathrm{OR})$ with 95\% confidence intervals $(\mathrm{CI})$ were calculated for individual alleles of the CTR gene in association with the stone disease.

\section{RESULTS}

The frequency distribution of the calcitonin gene polymorphism in patients with stone disease and healthy controls are presented in (Fig. 1) and Table 1 .

The bands on the gel (Fig.1) have been designated into three distinct groups: Cuttable (TT) uncuttable (CC) and heterozygous (TC). Figure 1 shows the allelic variant of CTR. The allelic distribution of $\mathrm{C}$ and $\mathrm{T}$ is presented in Table 1. No significance difference in allelic frequencies were observed between stone patients and control group Table $1(\mathrm{p}=.185)$. For the sake of comparison, the data is further subdivided into male and female groups and is, listed in (Table 2) The allelic frequencies when calculated separately for males and females also did not show any significance on comparison between the control and the stone formers. $(p=.869$ and .126) respectively In case of female gender when frequency was $>5$ according to Table 2 we compared the two groups (patient and control)

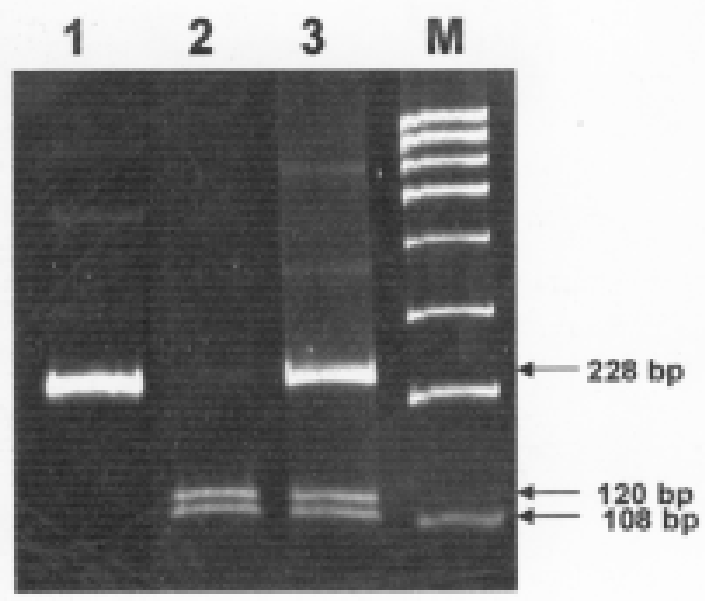

Fig. 1. PCR/Alu-I restriction digestion of the $1377^{\text {th }}$ allelic site in the CTR gene. The allelic variants of the CTR gene are indicated on the top of the gel; if only $\mathrm{C} / \mathrm{C}$ is present the $\mathrm{PCR}$ product is not digested by Alu-I enzyme, resulting in 228 bp fragment (CC allelic variant). If only $T / T$ is present the PCR product is digested by Alu-I enzyme in two 120 and 108 bp fragments (TT allelic variant). If $T / C$ is present half of the PCR product is cut and the other half is uncut resulting in a mixture of 228,120 and $108-$ bp fragments (T/C allelic variants) 
with three conditions ( TT,CC and CT) by two proportion analysis using NCSS 6.0 software. In CT, TT and CC the Odd's ratio were $0.756,0.792$ and 1.3 respectively at $95 \%$ confidence interval (CI).

\section{DISCUSSION}

The hormone calcitonin through its receptor is involved in maintaining calcium homeostasis. Amino acid leucine/proline variation in critical region of CTR protein is believed to bring about variation in receptor interaction with downstream pathway evolving cAMP (Nakamura et al. 1997; Chen et al. 2001). On this basis, the CTR gene polymorphism has been studied for its association with diseases involving calcium metabolism.

Our study demonstrated that a cuttable band (TT) of PCR product of CTR though prominent in stone patients $(13 \%)$ as compared to the normal individuals $(5.7 \%)$ was not statistically significant $(\mathrm{p}=.185)$. The individuals with the leucine allele (T) in the CTR gene are expected to have a high risk of calcium oxalate stone disease. In our population $5.7 \%$ in control group and (13\%) of leucine allele $(\mathrm{T})$ in stone patients were observed as compared to the Taiwanese population who reported 2\% (TT) in stone patients and absent in normal individuals (Chen et al. 2001). Their observation is rather unusual indicating 5.7\% as CT but TT as zero. The emergence of T allele in heterozygous state in their population is then questionable. Perhaps their study required a large

Table 1: Distribution of calcitonin receptor gene Alu1 polymorphism in control and stone patients

\begin{tabular}{lccccc}
\hline & $C C$ & $C T$ & $T T$ & Total & P-Value \\
\hline Control & 26 & 73 & 6 & 105 & \\
& $(24.8)$ & $(69.5)$ & $(5.7)$ & $(100)$ & 0.185 \\
Stone & 25 & 62 & 13 & 100 & \\
Patients(\%) & $(25)$ & $(62)$ & $(13)$ & $(100)$ & \\
\hline
\end{tabular}

number of control group to appreciate allelic polymorphic frequency in their normal population

Masi et al. (1998) in their study attributed the variation as risk factors for significant loss of minerals from bone thus causing higher susceptibility to fractures. Chen et al. (2001) on similar hypothesis analyzed the CTR Alu1 polymorphisms in stone patients and observed higher incidence of stone formation in individuals having higher $\%$ of $\mathrm{T}$ allele in Taiwanese population. Although the frequency of $\mathrm{T}$ allele in stone formers from our population was slightly higher than normal individuals but the differences were not statistically significant. Similarly, the differences in the distribution of the genotypes (CC, CT and TT) among the two groups were also insignificant. Although male patients had higher incidence of calcium oxalate stone disease as compared to the females, but here also, allelic and genotypic differences were not conspicuous.

There are considerable differences in normal allelic patterns in various populations of the world. The Caucasians (Masi et al. 1998; Wolfe et al. 2003) have predominantly $\mathrm{T}$ allele whereas Asians Japanese and Chinese and have $\mathrm{C}$ alleles (Nakamura et al. 1997; Chen et al. 2001). In North India, although $\mathrm{C}$ allele is higher than $\mathrm{T}$ allele, heterozygous genotypes predominated in the population. If presence of $T$ allele was an ideal risk factor for calcium oxalate stone disease, then there should have been higher incidence of the disease among Caucasians. However, epidemiological studies do not support major variations in incidence of stone disease. Therefore it seems that the CTR gene Alu1 polymorphism may not be a suitable genetic marker for screening for causes of calcium oxalate stones in Indian population. The variation in distribution of allelic frequencies and or inconsistency in CTR polymorphism may be due to different disease groups, sex or ethinicity

Table 2: Allelic frequency of $\mathrm{C} / \mathrm{T}$ polymorphism at the $1377^{\text {th nucleotide }}$ in calcitonin receptor gene in male / female stone formers and controls

\begin{tabular}{lccccc}
\hline & $C C$ & $C T$ & $T T$ & Total & P-Value \\
\hline Male & 11 & 15 & 2 & 32 & \\
Stone Patients & $(34.38 \%)$ & $(59.37 \%)$ & $(6.25 \%)$ & $(100 \%)$ & 0.869 \\
& 4 & 10 & 1 & 15 & \\
\hline Female & $(26.67 \%)$ & $(66.67 \%)$ & $(6.67 \%)$ & $(100 \%)$ & \\
& 15 & 54 & 7 & 73 & \\
Stone Patients & $(20.55 \%)$ & $(73.97 \%)$ & $(5.48 \%)$ & $(100 \%)$ & 0.869 \\
& 21 & 52 & 12 & 85 & \\
& $(24.71 \%)$ & $(61.18 \%)$ & $(14.12 \%)$ & $(100 \%)$ & \\
\hline
\end{tabular}


between European and Asians.

As this is a first preliminary report from North Indian patients in idiopathic calcium oxalate stone disease, further study of this polymorphism is needed Calcium oxalate disease is complex and does not correlate with a limited focus on calcium.

Therefore the search for candidate gene markers for calcium oxalate stone disease should be expanded beyond the narrow focus on calcium related factors.

\section{CONCLUSIONS}

The CTR gene polymorphism did not have significant association with the calcium oxalate stone disease. This probably suggests that CTR gene polymorphism is not an ideal genetic marker or candidate for calcium oxalate urolithiasis in our population. Yet with the growing information on mapped genes it is likely that these regions may contain the candidate gene which could provide further analysis either for tissue expression or clinical presentation in variety of groups.

\section{ACKNOWLEDGEMENT}

This study was supported by a grant from U.P Council of Science and Technology India

\section{REFERENCES}

Blin N, Stafford DWA 1976. A general method for isolation of high molecular weight DNA from eukaryotes. Nuc Acid Research, 3: 2303-2308.

Chen W, Wa H, Lu H, et al. 2001. Calcitonin receptor gene polymorphism: A possible genetic marker for patients with calcium oxalate stones. Eur Urol, 39: 716-719.

Coe FL, Parks JH, Asplin JR 1992. The pathogenesis and treatment of kidney stones. $N$ Engl J Med, 327: 1141-1152.

Danpure CJ 2000. Genetic disorders and urolithiasis. Urol Clin North Am, 27: 287-299.

Goodman HO, Brommage R, Assimos DG, et al. 1997. Genes in idiopathic calcium oxalate stone disease. World J Urol, 15: 186-194.

Loder N 1999. Genetic variations can point the way to disease gene. Nature, 401: 734 .

Masi L, Becherini L, Colli E, et al. 1998. Allelic variants of human Calcitonin receptor: Distribution and association with bone mass in postmenopausal Italian women. Biochem Biophys Res Commun, 245: 622626 .

Nakamura M, Zang Z, Shan L, et al. 1997. Allelic variants of human calcitonin receptor in the Japanese population. Human Genetics, 99: 38-41

Nicholson GC, Moseley JM, Sexton PM et al. 1986. Abundant Calcitonin receptors in isolated rat osteoclasts. Biochemical and autoradiagraphic characterization. J Clin Invest, 78: 355-360.

Wolfe 111 LA, Fling ME, Xue Z, et al. 2003. In vitro characterization of a human Calcitonin receptor gene polymorphism. Mutation Research, 522: 93-105. 